\title{
Myoparasitism: A Rare Differential in a Case of Parotid Swelling
}

\author{
Abhijit Kumar*, Ajay Gupta and Gautam Arora \\ Department of ENT and Head Neck Surgery, India
}

Submission: March 18, 2021; Published: April 28, 2021

*Corresponding author: Dr. Abhijit Kumar, MS Consultant, Department of ENT and Head Neck surgery, Tata Main hospital, Jamshedpur, Jharkhand, India

\section{Abstract}

Cysticercosis in human is caused by infection with the larval stage of Taenia solium. Muscular infestation is common in developing countries like India, but it rarely involves the head and neck region, and is often seen as a diagnostic dilemma for the clinician. Therefore, parotid cysticercosis is an uncommon entity, a diagnostic challenge especially in endemic regions of Asia, Africa and Latin America [1]. We report a rare case of 64-yearold man presented with a firm nodular swelling in left parotid region that was diagnosed as cysticercosis after all thorough investigations and managed medically.

Keywords: Cysticercosis; Taenia solium; Parotid swelling; Anthelmintic drugs; Parasitism

Abbreviations: CT: Computed Tomography; MRI: Magnetic Resonance Imaging

\section{Introduction}

Cysticercosis is a parasitic disease caused by larvae of Taenia solium also known as pork tapeworm. The etiopathogenesis is due to the ingestion of food, vegetables or water contaminated with $\mathrm{T}$. solium eggs or inadequately cooked pork containing cysticerci [1]. It is a "biological marker" of the social and economic development of a community [2]. Central nervous system, subcutaneous tissue, striated muscle, vitreous humour of eye are the most commonly affected sites. However, involvement of the head and neck region is uncommon for cysticercosis as very few cases have been reported in the parotid region and poses difficulty in clinical diagnosis [3]. Here we are presenting a rare case of parotid swelling where workup revealed it to be cysticercus cellulose.

\section{Case Presentation}

A 64-year-old relatively healthy male, yoga instructor by profession, moderately built, vegetarian, presented to the outpatient department with a swelling over the left side of face in front of the ear since last 4 days. The swelling was insidious in onset, gradually progressive since last 3 months which had rapidly increased in size in last 4 days associated with mild pain. Patient gave no history of trauma, tobacco chewing, smoking, difficulty chewing or talking, fever, weight loss, discharge from the swelling and no relevant previous family history.

Local examination revealed a single solitary swelling of size $3.5 \times 4 \mathrm{~cm}$, firm in consistency, mobile, spherical in shape, nonfluctuant, non-tender in nature on left side of the face extending horizontally from $1 \mathrm{~cm}$ below and anterior to the tragus upto the angle of mouth and vertically extending from the zygomatic process superiorly upto the body of mandible inferiorly, mild local rise of temperature over the skin was present. Lymph nodes around the area were not palpable. Mouth opening was adequate with fair oral hygiene. The following differential diagnosis were included: parotid sialadenitis, mumps, parotid abscess, parotitis, tubercular lymphadenitis, tumour (Figure 1).

Routine blood work up was within normal limits. Chest X-ray was normal. High resolution ultrasonography revealed an echoic cystic lesion measuring approximately $10 \times 9 \mathrm{~mm}$ with internal echoes in left the parotid region. Fine needle aspiration cytology was done and smears prepared, air dried and stained with Giemsa stain, Microscopic examination of the smear revealed mildly hyperplastic salivary acini with ductal cells and thin fibrovascular stroma with no evidence of granulomatous inflammation or 
malignancy. The patient was given a course of oral cefuroxime 500mg twice daily for 7 days and asked to follow up. There was no change in the size of swelling after 1 week of antibiotic. Subsequently a CECT face and neck was ordered which revealed well defined cystic lesion measuring approximately $11 \times 9 \mathrm{~mm}$ noted in the superficial layers of the left masseter muscle deep to parotid gland. The impression was cysticercosis (vesicular stage) in the left parotid region.

The patient underwent detailed neurology and ophthalmology review which were unremarkable. NCCT brain revealed no significant neuroparenchymal abnormality. Patient was managed conservatively with tablet Albendazole once daily for 21 days and advised a high fibre low protein diet. After the completion of anthelmintic pharmacotherapy, the swelling significantly reduced in size. Further a follow up ultrasonography revealed no evidence of any cystic lesions in the head and neck. After 3 months of follow up there was no evidence of residual or recurrent disease (Figure 2). The patient is currently doing well.
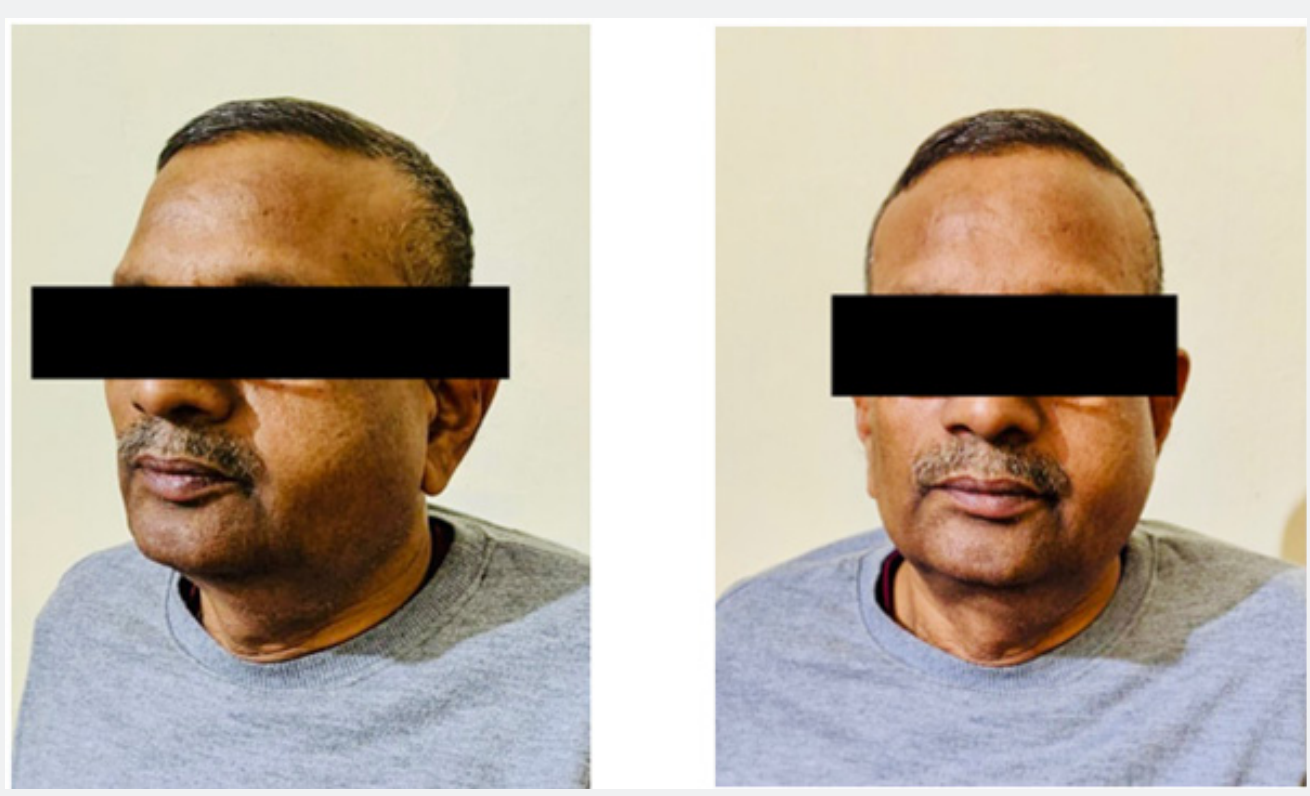

Figure1: Patient presented with swelling over left side of face.
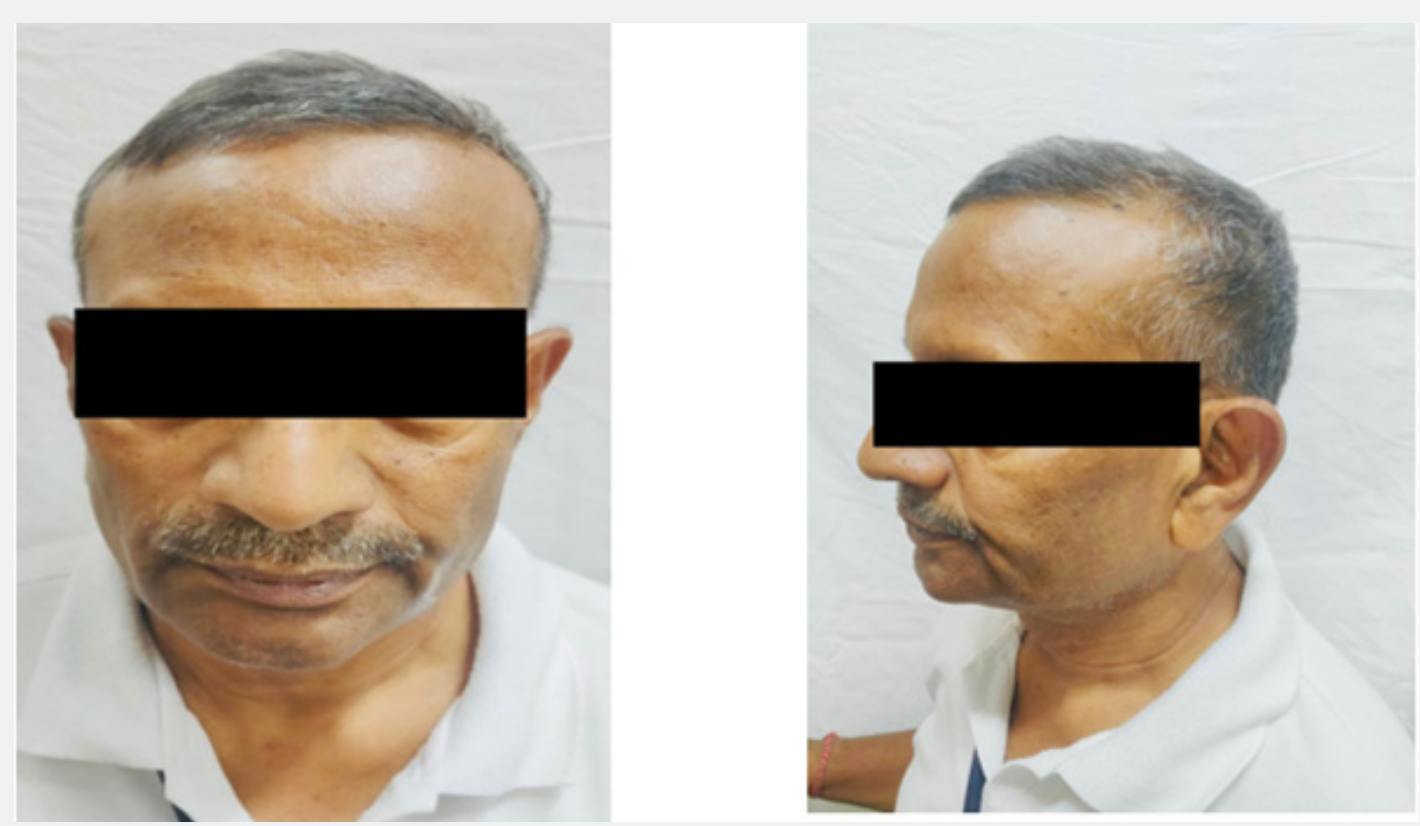

Figure 2: Patient 1 month after anthelminthic pharmacotherapy. 


\section{Discussion}

Cysticercus cellulose is the larval form of Taenia solium and presents as a larval infection produced by the cestodes [4]. The causative parasite of cysticercosis passes its life cycle in two hosts: Human is the definitive host as the adult worms live in the small intestine [1,2]. The intermediate host is pig which shelters the larval stage and cause cysticercosis. Human beings acquire cysticercosis through feco-oral contamination with Taenia solium eggs from tapeworm carriers $[3,5,6]$. Therefore, vegetarians and people who don't eat pork can acquire this infection. Water, wind, flies and other indirect means of infection play some part in its transmission.

An adult worm measures 3 meters in length with 1000 proglottids each of them containing approximately 50,000 eggs. The adult worm sheds their eggs in stool which are taken up by pigs and acts as the intermediate host. In the alimentary canal of the intermediate host, these eggs rupture and oncospheres are produced. The oncospheres penetrate the gut wall of pigs and reach their systemic circulation and enters various organs and muscles. It is over here that encystment of larval forms takes place and is termed as cysticercosis cellulose. The larval forms enter humans by the ingestion of contaminated food or water. The transmission of eggs via hands or carriers of the adult worm or internal autoinfection by regurgitation of eggs into the stomach can also lead to infection $[6,7]$.

The larval forms reach subcutaneous tissue, muscles, brain and ocular tissues via blood vessels and lymphatics. Clinically, the patient may remain asymptomatic or present with epigastric pain, nausea and diarrhoea. Sometimes, these larval encystment occur in oral and facial region. In majority of cases, cysticercosis presents with a solitary nodule and can be noted on trunk, upper arm, eyes, neck and rarely tongue, face and breast. In neurocysticercosis, the patient present with seizures and can be associated with skin nodules [8].

Radiological findings are not routinely used in the diagnosis of cysticercosis. The cysticercus cyst present with an inflammatory mass around it, irregular cyst with minimal fluid on one side and may appear as a large irregular collection of exudative fluid or seen as calcified mass [9]. FNAC and high-resolution ultrasonography are helpful in the diagnosis of cysticercosis. The patient should also be screened for any ocular and neurological involvement. The presence of fragment of larval bladder wall, hooklets and calcareous corpuscles confirms the diagnosis of cysticercosis. The background may be granular and reveal eosinophils, neutrophils, palisading histiocytes, giant cells. On ultrasonography it may appear as a cysticercus cyst with an inflammatory mass around it, as an irregular cyst with very minimal fluid on one side. Cytologically, other differential diagnosis which can be kept in mind are hydatid cyst which shows presence of protoscolices, hooklets, and fragments of the laminated membrane. In some cases, only laminated membranes are present in the inflammatory background. Cysticercosis must also be differentiated from abscesses and non-parasitic cysts [10-12].
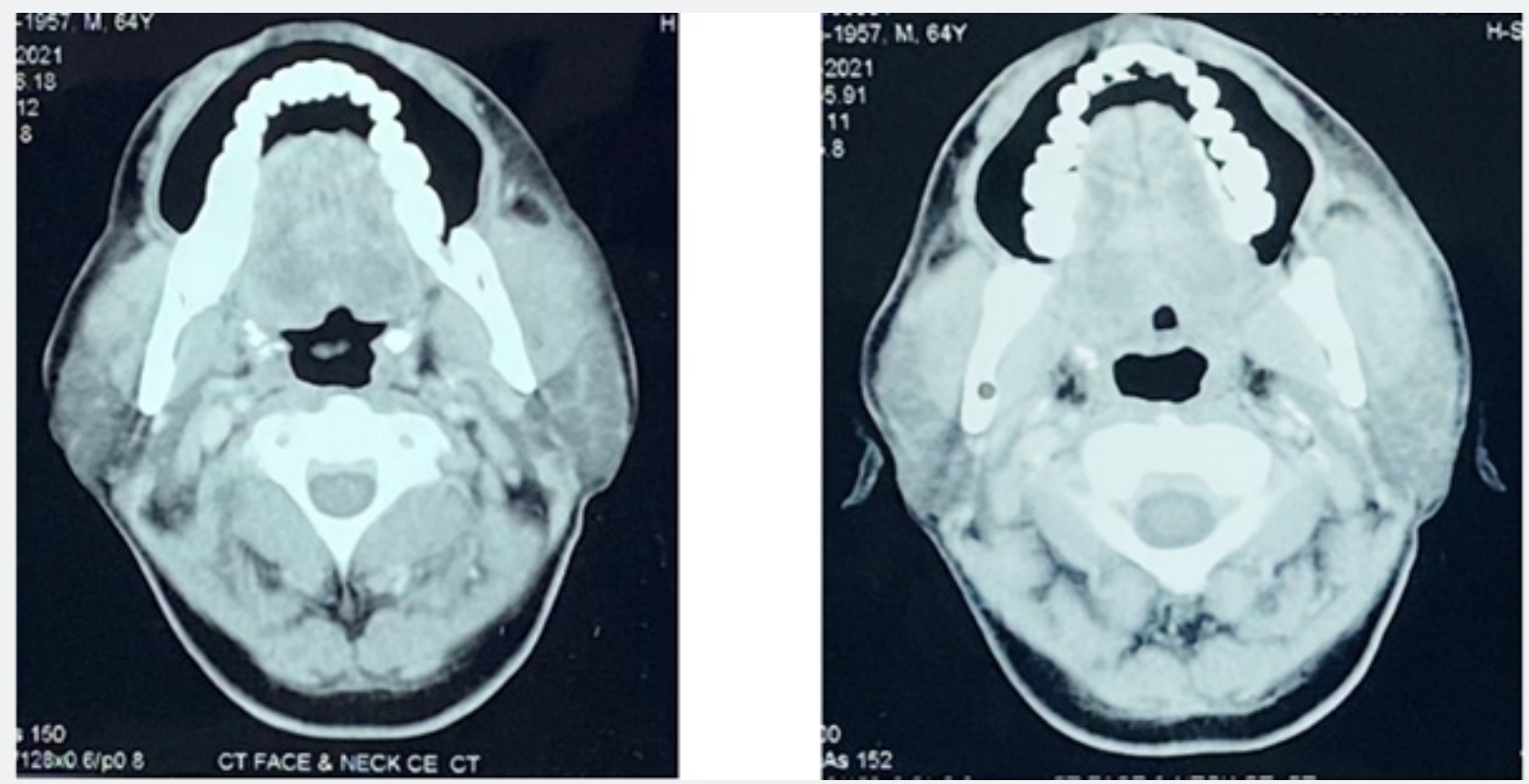

Figure 3: CT scan showing cystic lesion on the left side. 
Computed tomography (CT) and magnetic resonance imaging (MRI) have greatly improved the accuracy of diagnosis of cysticercosis. The vesicular stage of the cyst is seen on the CT as a hypodense area containing a hyperintense small scolex along with a nonenhancing or mildly enhancing cyst wall (Figure 3). CT depicts the colloidal vesicular stage as a ring enhancing cystic lesion with hyperintense fluid content and surrounding edema. In the granular nodular stage when the cyst retracts to form a nodule, the CT shows an enhancing nodule with mild surrounding edema. The final stage can be seen as single or multiple calcified nodules. MRI is considered best for the detection of a degenerating and innocuous (viable) cysticerci. It also helps in visualizing the perilesional edema very well. Hence, although MRI allows better detection of the active parasites, it can miss the calcified lesions, especially when the gradient echo sequence is not used; in which case a CT must be advised [7].

The standard treatment for facial or muscular cysticercosis is prescription of anthelmintic drugs like praziquantel and albendazole. Sometimes, corticosteroids such as prednisolone can be used in cases where there is associated inflammatory reaction. Effective preventive measures can also be taken like consumption of high fibre diet, well-washed vegetables, filtered or boiled water and proper hand washing before meals and preparation of food. Hence, medical management can heal most of the symptomatic lesions and surgery is not always required in muscular cysticercosis $[10,11]$.

\section{Conclusion}

Lesions in the facial region are uncommon, but cysticercosis should be kept as a clinical differential diagnosis in concurrence with dietary history and radiological findings. It is a global health problem with high prevalence in endemic countries like India. Improvement in the sanitary conditions, adequate treatment of sewage or feces, and educating public about personal hygiene such as hand washing can help in the prevention of human cysticercosis.

Previous studies have suggested FNAC and USG to be quick mode of investigation in diagnosing clinically unsuspected case of cysticercosis of facial region, but reports suggested that CT and MRI proved to be equally reliable diagnostic tools for the diagnosis of cysticercosis in the absence of a definitive pathological diagnosis as they help in assessing the relation of cyst to the surrounding structures and more effective in identifying cyst and scolex. Therefore, an early anthelmintic therapy (albendazole $15 \mathrm{mg} / \mathrm{kg} /$ day) can be started for 21 days that leads to the healing of most of the symptomatic lesions and the need for surgery can be avoided in case of muscular cystecercosis. However, the patient should be followed up for monitoring of therapeutic response and ophthalmologic or neurologic signs of cysticercosis cellulose to prevent any complications with the help of a CT or USG.

\section{References}

1. Sidhu R, Nada R, Palta A, Mohan H, Suri S (2002) Maxillofacial cysticercosis: Uncommon Appearances of a Common Disease. J Ultrasound Med 21(2): 199-202.

2. Nigam S, Singh T, Mishra A, Chaturvedi U (2001) Oral cysticercosis report of six cases. Head Neck 23(6): 497-499.

3. Pandey SC, Pandey SD (2005) Lingual cysticercosis. Indian J Plast Surg 38(2): 160-161.

4. Martinez MJ, De Aluja AS, Gemmell M (2000) Failure to incriminate domestic flies (Diptera: Muscidae) as mechanical vectors of Taenia eggs (Cyclophyllidea: Taeniidae) in rural Mexico. J Med Entomol 37(4): 489-491.

5. Reddi SP, Molares MJ, Addante RD (2001) Solitary lesion in the masseter muscle. J Oral Maxillofac Surg 59(1): 71-75.

6. Goyal P, Ghosh S, Sehgal S, Mittal D, Singh S (2014) Solitary Cysticercosis of Parotid Gland Diagnosed on FNAC. APSP J Case Rep 5(1): 11.

7. Mittal A, Das D, Iyer N, J Nagaraj, M Gupta (2008) Masseter cysticercosis-a rare case diagnosed on ultrasound. Dentatomaxillofac Radiol 37(2): 113-116.

8. Kala P, Khare P (2014) Fine-needle aspiration cytology as a diagnostic modality for cysticercosis: A clinicopathological study of 137 case. J Cytol 31(2): 68-72.

9. Vijayaraghavan SB (2004) Sonographic appearances in cysticercosis. J Ultrasound Med 23(3): 423-427.

10. Sekhar GC, Honavar SG (1999) Myocysticercosis: experience with imaging, therapy. Ophthalmology 106(12): 2336-2340.

11. Takayanagui OM, Chimelli L (1998) Disseminated muscular cysticercosis with myositis induced by praziquantel therapy. Am J Trop Med Hyg 59(6): 1002-1003.

12. Kumar BD, Dave B, Meghana SM (2011) Cysticercosis of masseter. Indian J Dent Res 22(4): 617. 
This work is licensed under Creative Commons Attribution 4.0 License

DOI: 10.19080/JHNSS.2021.04.555639

\section{Your next submission with Juniper Publishers will reach you the below assets}

- Quality Editorial service

- Swift Peer Review

- Reprints availability

- E-prints Service

- Manuscript Podcast for convenient understanding

- Global attainment for your research

- Manuscript accessibility in different formats

( Pdf, E-pub, Full Text, Audio)

- Unceasing customer service

Track the below URL for one-step submission https://juniperpublishers.com/online-submission.php 